\title{
Electrophysiological Responses in the Human Amygdala Discriminate Emotion Categories of Complex Visual Stimuli
}

\author{
Hiroyuki Oya, Hiroto Kawasaki, Matthew A. Howard III, and Ralph Adolphs \\ Departments of Neurology and Neurosurgery, University of lowa College of Medicine, lowa City, lowa 52242
}

The human amygdala has been shown to participate in processing emotionally salient stimuli related to threat, danger, and aversion, data that have come primarily from functional imaging and lesion studies. Recording intracranial field potentials from five amygdalas in four patients with chronically implanted depth electrodes, we analyzed responses in the gamma frequency range, a region of the power spectrum thought to reflect especially the contribution of neuronal activity to cognitive processes. Significant changes in the power amplitude of responses were obtained selectively to visual images judged to look aversive but not to those judged to look pleasant or neutral. Several possible confounds were addressed: all four patients had been carefully selected so that the amygdalas from which recordings were obtained were distal to epileptogenic foci, making it likely that we recorded from healthy tissue, and the observed responses could not be attributed to luminance or color differences between the stimuli. A further analysis of differences in power between the high and low gamma bands revealed an additional structure that discriminated those stimuli related to bodily injury from those related to disgust. Despite the increased power amplitude in the gamma range, there was no stimulus-locked phase coherence. The observed responses in the gamma frequency range may reflect the role of the amygdala in binding perceptual representations of the stimuli with memory, emotional response, and modulation of ongoing cognition, on the basis of the emotional significance of the stimuli.

Key words: amygdala; human; intracranial recording; local field potential; gamma oscillation; emotion
A large number of studies in animals have implicated the amygdala in the processing of emotionally salient stimuli (Weiskrantz, 1956; LeDoux, 1996; Rolls, 1999). In humans, functional imaging and lesion studies have suggested a role for the amygdala in processing auditory (Phillips et al., 1998), gustatory (Zald et al., 1998; O'Doherty et al., 2001), and olfactory stimuli (Zald and Pardo, 1997; Royet et al., 2000) that signal or induce unpleasant emotions. In the visual modality, the amygdala is activated by emotionally salient stimuli, especially those related to threat, danger, or aversion (Irwin et al., 1996; Lane et al., 1997; Liberzon et al., 2000), including facial expressions of fear (Breiter et al., 1996; Morris et al., 1996; Whalen et al., 1998, 2001), whose recognition is impaired after bilateral amygdala damage (Adolphs et al., 1994; Calder et al., 1996).

Both functional imaging and lesion studies of the amygdala suffer from imprecise temporal and spatial localization, a limitation that can be overcome with intracranially recorded field potentials. Of special interest is brain electrical activity in the gamma frequency range $(20-80 \mathrm{~Hz})$, which has been reported in regions including the visual cortex (Gray et al., 1989; Eckhorn, 1994), somatosensory cortex (Bouyer et al., 1987; Jones and Barth, 1997), motor cortex (Murthy and Fetz, 1992), olfactory bulb (Freeman, 1972; Eeckman and Freeman, 1990), auditory cortex (MacDonald et al., 1996, 1998), hippocampus (Buzsaki,

\footnotetext{
Received April 3, 2002; revised Aug. 12, 2002; accepted Aug. 12, 2002.

This work was supported by grants from the EJLB Foundation, the Klingenstein Fund, and the James S. McDonnell Foundation. We thank Igor Volkov, Olaf Kaufman, Yota Kimura, and Soman Puzhankara for help with the experiments and data analysis, Mark Granner for providing epilepsy center services, and Daniel Tranel and Natalie Denburg for help with background neuropsychological testing.

Correspondence should be addressed to Ralph Adolphs, Department of Neurology, 200 Hawkins Drive, Iowa City, IA 52242. E-mail: ralph-adolphs@uiowa.edu. Copyright (C) 2002 Society for Neuroscience $0270-6474 / 02 / 229502-11 \$ 15.00 / 0$
}

1986; Traub et al., 1996), and entorhinal cortex (Chrobak and Buzsaki, 1998) and has been linked to several specific aspects of neural function (Sannita, 2000). Gamma oscillations play a role in selective attention, associative learning, ambiguous perception, visuomotor integration, and emotional evaluation (Tiitinen et al., 1993; Roelfsema et al., 1997; Miltner et al., 1999; Müller et al., 1999; Rodriguez et al., 1999). The possible contribution of gamma oscillations to emotional processing has been investigated in studies using scalp EEG (Müller et al., 1999, 2000; Taylor et al., 2000; Keil et al., 2001). Müller et al. (2000) found gamma band responses to aversive and pleasant emotional pictures, and Keil et al. (2001) reported early and late gamma components in response to emotional pictures. Integrating and binding among the disparate features of complex perceptual representations thus appear to be key roles of gamma synchronizations and oscillations, roles that may extend to the association of the visual properties of stimuli with their emotional significance.

To provide further detail to the role of the amygdala in processing emotional visual stimuli, we recorded field potentials from the amygdalas of four patients while we showed them complex images that varied in terms of their emotional meaning. We selected patients in whom we could record from amygdalas that were not associated with seizure foci, and we controlled for possible differences in luminance and color between emotional stimuli. Our analyses of gamma range power spectra separated amplitude and phase information and examined these components of the neuronal response as a function of the emotion category of the stimuli.

\section{MATERIALS AND METHODS}

Subjects and electrode implantation

Four patients with pharmacologically refractory epilepsy (two male and two female) participated in this research. All four patients had complex 
Table 1. Demographic and neuropsychological information

\begin{tabular}{|c|c|c|c|c|c|c|c|c|c|}
\hline Patient & Age & Sex & $\begin{array}{l}\text { Language } \\
\text { dominance }\end{array}$ & VIQ & PIQ & Visual-perception & Depression & $\begin{array}{l}\text { Language } \\
\text { function }\end{array}$ & $\begin{array}{l}\text { Executive } \\
\text { function }\end{array}$ \\
\hline 66 & 30 & Female & Left & 125 & 110 & 50 & None & Normal & Normal \\
\hline 70 & 39 & Male & Right & 92 & 95 & 50 & None & Normal & Normal \\
\hline 74 & 46 & Male & Left & 110 & 120 & 43 & None & Normal & Normal \\
\hline 77 & 30 & Female & Left & 97 & 108 & 49 & None & Normal & Normal \\
\hline
\end{tabular}

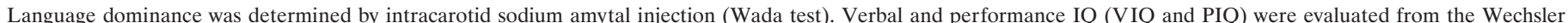

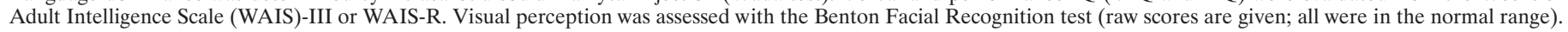

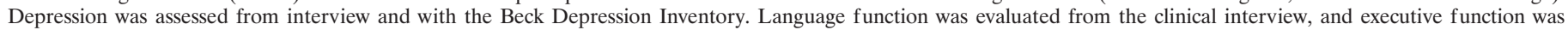
assessed with the Trailmaking test.

partial seizures whose foci could not be adequately localized by noninvasive methods such as scalp EEG. To aid localization, depth electrodes were surgically implanted in the medial temporal lobe, under a clinical protocol. Electrodes stayed in place chronically for 2-3 weeks, during which time the patients elected to participate in our research studies. Implantation sites were chosen solely on the basis of clinical criteria.

All patients had normal or corrected-to-normal vision and had no history of head trauma or encephalitis. Preoperative structural magnetic resonance imaging (MRI) did not reveal any structural abnormalities in the amygdalas of any of the patients. Neuropsychological assessment of the patients before surgery confirmed normal cognitive functioning (Table 1). Patient 66 had seizures that were eventually localized to the left posterior temporal lobe, distal from the amygdala. Patient 70 had seizures originating from the lateral surface of left or right posterior temporal lobe, or both, that again showed no involvement of the amygdala in the origin of the seizure. Patient 74 had seizures arising from right temporal lobe, and no evidence was found of abnormal electrical activity within the left amygdala from which we recorded. Patient 77 had seizures arising from a cystic mass in the posterior part of the right inferior temporal gyrus with no involvement of the amygdala. Thus it is probable that our recordings were made from normally functioning amygdalas in the four patients, because their seizure foci were located in extra-amygdalar structures, and no structural abnormalities were evident within the amygdalas recorded on MR scans.

We implanted clinical-research hybrid depth electrodes consisting of a tecoflex-polyurethane shaft $(1.25 \mathrm{~mm}$ outer diameter $)$ with eight highimpedance research contacts $(50-\mu \mathrm{m}$-diameter platinum-iridium wires cut flush with the shaft surface) and two low-impedance contacts used only for clinical monitoring (Howard et al., 1996; Kawasaki et al., 2001). Electrodes were implanted under general anesthesia using a CosmanRoberts-Wells stereotactic system (Radionics, Burlington, MA) and guided by anatomical information available from preoperative MRI. Localization of the electrodes was subsequently confirmed with MRI that was performed immediately after implantation and that permitted detailed three-dimensional reconstruction of recording sites (Fig. 1) (Damasio and Frank, 1992; Frank et al., 1997). Recordings were bipolar, obtained from research contacts separated by $\sim 200 \mu \mathrm{m}$. Intercontact impedance ranged from 90 to $200 \mathrm{k} \Omega$ at $1 \mathrm{kHz}$. A single recording channel thus corresponds to one pair of research contacts providing a bipolar recording. The research protocol was approved by the Human Subjects Committee of the University of Iowa, and written informed consent was obtained from all participants.

\section{Visual stimuli and presentation}

Emotional visual stimuli were selected from the International Affective Picture Series (IAPS; Lang and Cuthbert, 1993), which provided normative ratings of valence (ratings of the pleasantness as high valence or unpleasantness as low valence) and arousal on a scale from 1 to 10 and which has been widely used for the study of emotion (Kubota et al., 2000; Northoff et al., 2000). For the majority of stimuli, ratings of valence and arousal were not independent but instead showed the pattern depicted in Figure 2; there were relatively few stimuli that had high arousal but neutral valence and few that had low arousal but strong emotional valence (either high or low). Because of these covariances, arousal and valence ratings for the stimuli could not be manipulated entirely independently (Lang et al., 1993; Russell and Carroll, 1999). We chose to divide the stimuli into three broad categories on the basis of their valence ratings: aversive (valence $<4$ and arousal $>4$ ), pleasant (valence $>6$ and arousal $>3$ and $<6.5$ ) and neutral (valence $>4$ and $<6$ and arousal
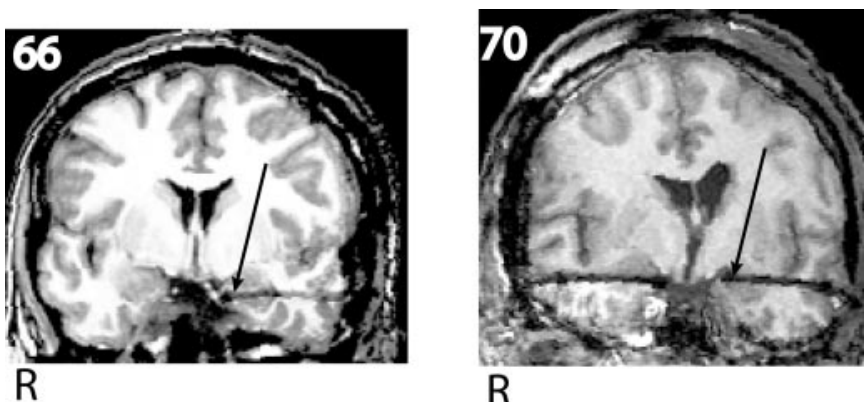

$\mathrm{R}$

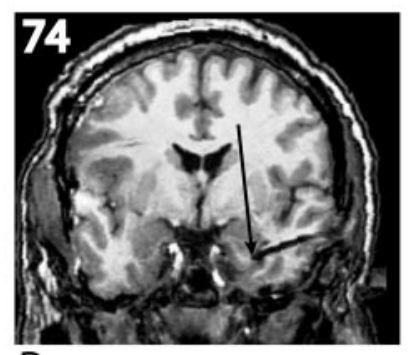

$\mathrm{R}$

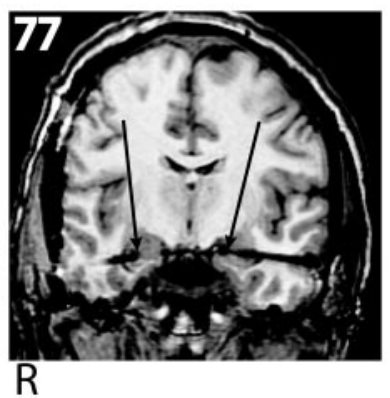

Figure 1. Anatomical localization of hybrid depth electrodes and recording site for each subject. Structural MR images (1.5 T, $1.5 \mathrm{~mm}$ thickness) were obtained immediately after implantation of the electrodes. Note that electrodes appear thicker than they are because of a paramagnetic signal artifact. Arrows indicate the recording site within the amygdala. Following radiological convention, the right side of the brain $(R)$ is shown on the left.

$<3.5$ ). We used 100 images in all, 34 classified as aversive, 32 as pleasant, and 34 as neutral (Fig. 2). Examples included pictures of burn victims and mutilated faces (aversive), pictures of puppies and happy family scenes (pleasant), and pictures of books and furniture (neutral). Two classes of pleasant stimuli, erotic images and pictures of food, were not included in the study because of the variable ratings given by subjects. Further details regarding the aversive stimuli are provided in Table 2 .

Between 4 and $14 \mathrm{~d}$ after electrode implantation, dependent on the patient's recovery from surgery, subjects were shown 30 randomly selected stimuli from each of the three emotion categories (for a total of 90 stimuli, presented in random order). A second experiment was performed on a separate day with one of the patients (patient 77) but had to be aborted because of fatigue, resulting in a total of only 68 stimuli in this second experiment ( 21 aversive, 24 pleasant, and 23 neutral).

Whereas the stimuli were selected randomly from the entire set of 100 for three of the patients, patient 66 was shown the same 30 stimuli three times (three repetitions of 10 each of neutral, pleasant, and aversive), thus permitting us to explore the possible effects of repeated presentations of the same stimulus on the responses recorded.

The experiments were postponed if the patient had a seizure within 12 $\mathrm{hr}$ before the planned recording session. Stimuli were shown as color digital images on a 14-inch liquid crystal display (LCD) monitor located $1 \mathrm{~m}$ in front of the subjects in a darkened, quiet room. Stimulus duration was $1 \mathrm{sec}$, with a randomly variable interstimulus interval that ranged from 5.0 to $8.0 \mathrm{sec}$ (to minimize any possible anticipatory responses). 


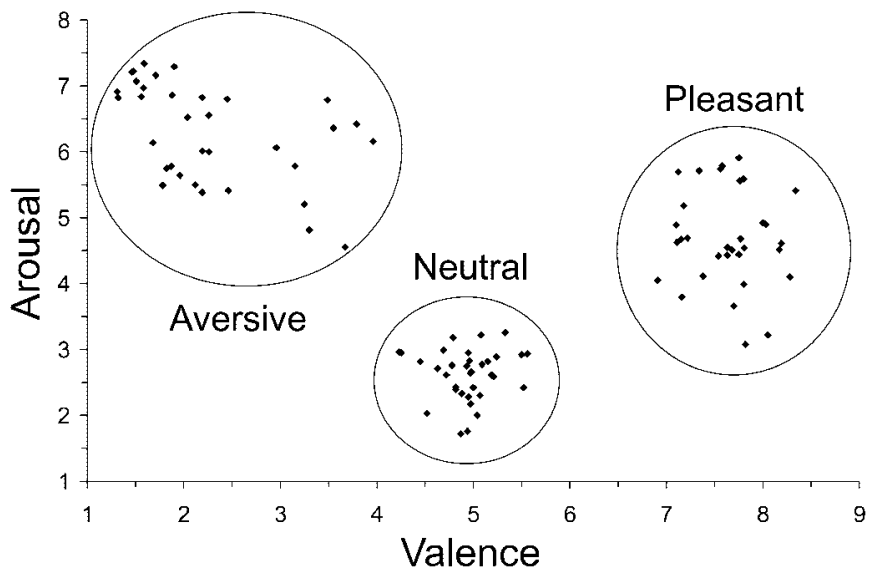

Figure 2. Arousal and valence ratings of stimuli. Mean normative ratings are shown for 100 color images chosen from IAPS and were used to classify the stimuli into three emotion categories (circled regions).

Stimulus presentation was controlled by PsyScope software (Macwhinney et al., 1997; Yee and Vaughan, 1999) on an Apple Macintosh computer. Patients sat comfortably in their beds and were instructed to maintain their gaze on the LCD monitor, to avoid head movement, and to passively watch the stimuli. The wakefulness and gaze of the subject were continuously watched by one of the investigators. All patients appeared alert and attentive for the duration of the experiments analyzed here.

\section{Local field potential recordings}

Continuous bipolar differential recordings were amplified $(5000 \times)$, bandpass-filtered $(1 \mathrm{~Hz}-6 \mathrm{kHz}$, Neurodata Amplifier; Grass Telefactor Inc.), and recorded on a multichannel analog tape recorder (StorePlus VL; Racal Instruments Inc.) together with a trigger signal indicating stimulus onset. Recorded signals were filtered off-line (1-300 Hz, eightpole Bessel filter, model 3384; Krohn-Hite Inc.), digitized using a DataWave Experimenter's Workbench (at $20 \mathrm{kHz}$; DataWave Technologies), and stored for further analysis.

\section{Signal processing}

We recorded local field potentials from a total of 35 bipolar channels (24 in the left amygdala and 11 in the right amygdala) to yield recordings from an initial 2974 trials. To reduce the amount of computation and minimize phase distortion, the raw signal was decimated using a digital finite impulse response filter with a 50-point Hamming window to yield a final sampling rate of $1 \mathrm{kHz}$. The decimated field potential signals were divided into trial sweeps that encompassed a $1 \mathrm{sec}$ prestimulus period followed by a $1 \mathrm{sec}$ poststimulus period. To reject trials that might be contaminated with noise, we calculated means and SD (from a logarithmic transform of the power amplitudes that normalized their distributions) and rejected any trials whose amplitude exceeded 5 SD above the mean. In addition, every trial was visually inspected to detect and reject trials containing movement artifacts or electrical interference. The overall rejection rate was $10.1 \%$ (299 trials were rejected of the initial 2974 trials); there was no association between rejection rate and emotional category of the stimuli $\left(\chi^{2}=3.26 ; p=0.196\right)$.

To obtain the time-frequency characteristics of the local field potential, trial signals were digitally convolved with a complex Morlet wavelet (a function that has the shape of a modulated Gaussian in the time domain and a simple Gaussian in the frequency domain and whose Fourier transform has no negative component). This wavelet analysis has been very successful in the analysis of biomedical time series data, because it minimizes the time-frequency spread and reduces the interference between positive and negative frequency components (Sinkkonen et al., 1995; Tallon-Baudry et al., 1995; Carmona et al., 1998; Mallat, 1998; Teolis, 1998; Csibra et al., 2000). The complex Morlet wavelet, $w\left(t, f_{0}\right)$ is specified as:

$$
w\left(t, f_{0}\right)=\left(\sigma^{2} \pi\right)^{-1 / 4} \exp \left(-t^{2} / 2 \sigma^{2}\right) \cdot \exp \left(2 \pi j f_{0} t\right),
$$

where $j$ is the imaginary unit value, $f_{0}$ is the center frequency, and $\sigma$ specifies the width of the wavelet. A feature of the Morlet wavelet is that it captures an invariant amount of energy regardless of the center frequency. In our analysis, we set the constraint ratio as $2 \pi f_{0 \sigma}=7.0$, and center frequencies ranged from 20 to $60 \mathrm{~Hz}$ in $2 \mathrm{~Hz}$ intervals. As an example, the wavelet width (2 SD of the envelope in the time domain) at a center frequency of $40 \mathrm{~Hz}$ was $55.7 \mathrm{msec}$.

The power envelope of the signal, $E\left(t, f_{0}\right)$, can now be calculated from the squared absolute value of the convolved data:

$$
E\left(t, f_{0}\right)=\left|w\left(t, f_{0}\right) * \operatorname{sig}(t)\right|^{2},
$$

where $\operatorname{sig}(t)$ is the field potential signal, $w\left(t, f_{0}\right)$ is the wavelet, and * denotes the convolution operator. To quantify the event-related change in the power envelope that might occur on presentation of a stimulus, we first calculated the median power envelope values from reference periods, $\operatorname{Ref}\left(f_{0}\right)$, sampled from $500 \mathrm{msec}$ before the onset of stimuli. We chose to calculate medians rather than means to describe the central tendency, because the distribution of power envelopes was non-normal and positively skewed. The values of event-related band power change (ERBP) at time $t$ with respect to the reference period is given by the following equation (Gasser et al., 1982; Fernández et al., 1995; Wei et al., 1998):

$$
\operatorname{ERBP}\left(t, f_{0}\right)=10 \cdot \log \left[E\left(t, f_{0}\right) / \operatorname{Ref}\left(f_{0}\right)\right](\mathrm{dB}) .
$$

This equation resulted in ERBPs that were normally distributed, as confirmed with Kolmogorov-Smirnov tests. We calculated ERBP values for all trials.

To evaluate the degree of phase locking from the filtered traces, we calculated phase-locking values (PLVs; Tallon-Baudry et al., 1996; Rosenblum et al., 1998; Tass et al., 1998; Lachaux et al., 1999; Le Van Quyen et al., 2001) defined by the following equation:

$$
\operatorname{PLV}\left(t, f_{0}\right)=1 / N \cdot\left|\sum_{\text {trial }} \exp \left[j \cdot \theta\left(t, f_{0}\right)\right]\right|,
$$

where $N$ is the number of trials, and $\theta$ is the instantaneous phase of a trial at a certain time $t$. The function $\theta\left(t, f_{0}\right)$ can be calculated by separating the imaginary and real components of the complex wavelet-transformed data as follows:

$$
\theta\left(t, f_{0}\right)=\arctan \left[\operatorname{imag}\left[w\left(t, f_{0}\right) * \operatorname{sig}(t)\right] / \operatorname{real}\left[w\left(t, f_{0}\right) * \operatorname{sig}(t)\right]\right] .
$$

The PLV thus obtained maps the phase onto a unit circle in the complex plane and represents phase stability over multiple trials. A value of $\mathrm{PLV}=1$ represents complete phase locking (the signals from all the different trials are exactly in phase), and a value of PLV $=0$ represents a uniformly distributed phase (the signals from the different trials have a random phase relationship). We calculated PLV only for the range 20-50 $\mathrm{Hz}$ to avoid possible contamination and spurious phase locking by $60 \mathrm{~Hz}$ noise.

\section{Statistical analysis}

The time-frequency plane was divided into 12 blocks, namely, two frequency bands (lower gamma, center frequencies of $20-34 \mathrm{~Hz}$; and higher gamma, center frequencies of $36-60 \mathrm{~Hz})$ and six time windows $(1$, prestimulus, $-100 \mathrm{msec}$ to stimulus onset; 2 , poststimulus, $50 \sim 150 \mathrm{msec}$; 3, 150 250 msec; 4, 250 350 msec; 5, 350 450 msec; and 6, 450 550 msec.). Mean values of the ERBP data in these 12 time-frequency windows were calculated for each trial and used for statistical analysis. Before conducting parametric statistical tests, the normality of the cumulative distributions of these values were assessed with KolmogorovSmirnov goodness-of-fit tests. We first chose recording channels that showed a significant ERBP change across these six time epochs by separately calculating, for each of the three emotion categories, one-way repeated measures ANOVAs with the six time windows as a withinsubjects factor and the single-trial ERBP values in that channel as the dependent measure (data were collapsed across all frequencies in this analysis). In this analysis, we considered $p<0.017(0.05 / 3)$ as statistically significant to control for multiple comparisons across the three emotion categories. Channels that showed a significant main effect of the time window in at least one emotion category were included in the analyses presented below. Single-trial ERBP values in the selected channels were averaged for each channel and entered into subsequent statistical analyses. Mean ERBP values were assessed by $6 \times 2 \times 3$ three-way repeated measures ANOVA with factors of time window, frequency range, and stimulus categories. Post hoc multiple comparisons used Tukey's honestly significant difference (HSD) test; Huynh-Feldt corrected degrees of freedom were used to correct for inhomogeneity of variance and covari- 
Table 2. Recording channels showing significant responses

\begin{tabular}{|c|c|c|c|c|c|c|c|c|c|}
\hline \multirow[b]{3}{*}{ Patient } & \multirow[b]{3}{*}{ Session } & \multirow[b]{3}{*}{ Channel } & \multirow[b]{3}{*}{ Side } & \multicolumn{6}{|c|}{ Stimulus category } \\
\hline & & & & \multicolumn{2}{|l|}{ Aversive } & \multicolumn{2}{|c|}{ Pleasant } & \multicolumn{2}{|l|}{ Neutral } \\
\hline & & & & $p$ & $n$ & $p$ & $n$ & $p$ & $n$ \\
\hline 66 & 1 & 5 & Left & $<0.001 *$ & 29 & 0.245 & 25 & 0.42 & 24 \\
\hline 66 & 1 & 7 & Left & $0.012 *$ & 28 & 0.27 & 27 & $0.001^{*}$ & 27 \\
\hline 66 & 1 & 8 & Left & $0.016^{*}$ & 29 & 0.078 & 26 & $<0.001^{*}$ & 26 \\
\hline 70 & 1 & 7 & Left & $0.012^{*}$ & 29 & 0.68 & 28 & 0.99 & 28 \\
\hline 74 & 1 & 1 & Left & $0.015^{*}$ & 27 & 0.25 & 30 & 0.67 & 29 \\
\hline 74 & 1 & 2 & Left & $0.004 *$ & 26 & 0.78 & 26 & 0.34 & 28 \\
\hline 77 & 1 & 1 & Right & $0.016^{*}$ & 25 & 0.058 & 17 & 0.442 & 28 \\
\hline 77 & 2 & 1 & Right & $0.015^{*}$ & 16 & 0.32 & 17 & $0.008^{*}$ & 22 \\
\hline 77 & 2 & 5 & Left & $0.010^{*}$ & 17 & 0.63 & 17 & 0.36 & 20 \\
\hline 77 & 2 & 6 & Left & $0.007^{*}$ & 16 & 0.35 & 17 & $0.014^{*}$ & 21 \\
\hline 77 & 2 & 7 & Left & $0.007 *$ & 16 & 0.625 & 17 & 0.117 & 21 \\
\hline 77 & 2 & 8 & Left & $0.015^{*}$ & 16 & 0.435 & 16 & $<0.001^{*}$ & 18 \\
\hline
\end{tabular}

ERBP responses were initially evaluated with repeated-measures ANOVAs (see Materials and Methods). Channel numbers, side of recording (left or right amygdala), $p$ values, and numbers of trials $(n)$ are shown for the three emotion categories.

${ }^{*} p<0.017$ was considered significant.

ances in the repeated measures (Huynh and Feldt, 1980; Bagiella et al., 2000). Original degrees of freedoms and Huynh-Feldt $\epsilon$ values are reported.

To assess the statistical significance of the PLV, we used resampling statistics. To correct for slight biases attributable to the unequal number of trials among different emotion categories, data in each channel were first randomly resampled 200 times (without replacement within each resample) using a sample size that was equal to the minimum number of trials originally present in any of the three emotion categories. A histogram of the cumulative resampling distribution was then obtained from the bias-corrected PLV data by resampling 5000 prestimulus time epochs of $500 \mathrm{msec}$ duration. One-tailed $p$ values of the poststimulus PLV were then calculated directly from this resampling distribution (Efron, 1979; Manly, 1997). Other statistical analyses were two-tailed, and $\alpha$ values were set to 0.05 unless otherwise specified. Signal processing and statistical analyses were done using MATLAB (Mathworks Inc.) and SPSS.

\section{Additional analyses}

Luminance and color of stimuli. We analyzed the mean luminance, and the luminance in each of three color channels (red, green, and blue) for our stimuli using the histogram function in Adobe Photoshop.

Sorting of stimuli. For an investigation of possible subcategories of stimuli revealed through our field potential analysis, we asked 10 naïve, normal subjects to sort printed photographs of the stimuli into two piles. As described in more detail in Results, we chose 10 stimuli within each emotion category whose ERBP responses showed the most positive difference between the high and low gamma ranges and those 10 stimuli that showed the most negative difference between high and low gamma ERBP (compare with Table 2 for aversive stimuli). Subjects were instructed to sort the stimuli in two piles of any size using whatever strategy they deemed most salient. The significance of the overlaps of the sorted piles with the categories shown by the ERBP analysis was assessed using the binomial distribution.

\section{RESULTS}

\section{Neuroanatomical location of recording sites}

Recording site locations were verified to be in the amygdala with postimplantation MRI scans; however, they were not all within the same region of the amygdala, an issue we comment on further in Discussion. As Figure 1 shows, we recorded from medial (patients 66, 70, and 77), lateral (patients 74 and 77), anterior (patient 70), and posterior (patient 77) regions within the amygdala. Four recording sites were on the left, and one was on the right. Although our sampling of different anatomical sites within the amygdala is too sparse at this time to permit a formal investigation of the responses seen in different amygdala nuclei, it is hoped that our future accrual of data or combination of data from different laboratories may shed light on the possible differences in responses obtained from different amygdala nuclei.

\section{Significant ERBP responses}

On the basis of our initial statistical analysis (see Materials and Methods), 12 of 35 total channels (34.3\%) showed statistically significant ERBP changes over time in at least one emotion category. Ten of these channels were located in the left amygdala, and two were in the right amygdala. All 12 channels showed significant responses to aversive stimuli, five also for neutral stimuli, and none for pleasant stimuli (Table 3 ). The total number of trials for these 12 channels was 274 for aversive stimuli, 263 for pleasant stimuli, and 292 for neutral stimuli (for a grand total of 829 trials). There was no statistically significant relationship between numbers of rejected trials and stimulus categories $\left(\chi^{2}=\right.$ 4.54; $p=0.103)$.

\section{Analysis of power envelope (ERBP)}

In analyzing the ERBP, a previous ANOVA demonstrated that there was no effect of the side of the recording channel (left or right amygdala), and we therefore pooled ERBP data from all the 12 channels shown in Table 3 in subsequent analyses. An examination of the response to each of the three emotion categories as a function of time and frequency (averaged across all 12 channels) showed a strong response to aversive stimuli with a complex pattern in frequency and time (Fig. 3). As can be seen from an examination of Figure 3, the gamma response appeared at $\sim 130$ msec after stimulus onset and lasted $\sim 80-180 \mathrm{msec}$. To assess the statistical significance of these responses, we performed a threeway (time $x$ frequency band $\times$ emotion category) repeated measures ANOVA on the responses averaged within all 12 channels. There was a strong main effect of Time $\left(F_{(5,165)}=15.6\right.$; no correction; $p<0.001)$. Post hoc Bonferroni-corrected $t$ tests indicated that overall responses were significantly different from before stimulus in the poststimulus $150-250 \mathrm{msec}(p<0.001)$, 250-350 msec $(p<0.001), 350-450 \mathrm{msec}(p<0.001)$, and $450-550 \mathrm{msec}(p<0.001)$ time windows, with maximal response in the $150-250 \mathrm{msec}$ window. The two-way time $\times$ frequency 
Table 3. IAPS numbers, mean ERBP values (dB) in the high- and the low-gamma range, and brief description of aversive stimuli

\begin{tabular}{|c|c|c|c|c|}
\hline IAPS number & High gamma & Low gamma & $n$ & Description \\
\hline 1201 & -3.51 & 2.99 & 2 & Big spider on shoulder \\
\hline 1275 & -0.6 & 0.77 & 5 & Roaches \\
\hline 2730 & -0.26 & -0.41 & 4 & Boy and cow \\
\hline 1930 & 0.23 & -2.97 & 4 & Shark \\
\hline 9571 & 1.8 & -0.18 & 4 & Dead cat \\
\hline 9520 & 2.18 & -1.54 & 8 & Kids in pollution \\
\hline 3170 & 2.26 & 3.56 & 13 & Cancer tumor \\
\hline 9570 & 2.44 & 3.78 & 3 & Rotting dog \\
\hline 3261 & 2.63 & -1.34 & 4 & Mutilation \\
\hline 9921 & 2.73 & 7.05 & 5 & Fire \\
\hline 3071 & 2.98 & -2.21 & 7 & Slashed throat \\
\hline 9560 & 3.15 & 0.39 & 8 & Duck in oil \\
\hline 9440 & 3.33 & 2.68 & 11 & Skulls \\
\hline 3530 & 3.36 & 3.78 & 18 & Gun in mouth \\
\hline 6350 & 3.36 & 2.45 & 9 & Man with knife \\
\hline 1070 & 3.71 & 2.67 & 9 & Snake \\
\hline 3000 & 3.77 & 0.11 & 9 & Mutilation \\
\hline 3062 & 3.87 & -0.3 & 3 & Mutilation \\
\hline 9630 & 3.95 & 7.54 & 7 & Bomb \\
\hline 3150 & 4.02 & 3.86 & 8 & Cut finger \\
\hline 3080 & 4.11 & -1.4 & 18 & Mangled face \\
\hline 1111 & 4.27 & -0.01 & 4 & Snakes \\
\hline 2800 & 4.33 & -0.69 & 9 & Crying boy \\
\hline 9300 & 4.36 & 10.23 & 9 & Dirty toilet \\
\hline 6540 & 4.42 & 3.52 & 9 & Man with knife \\
\hline 3130 & 4.58 & 5.56 & 14 & Body \\
\hline 3053 & 5.51 & 0.42 & 13 & Burn victim \\
\hline 1300 & 5.86 & 3.6 & 10 & Attacking pit bull \\
\hline 3010 & 6.13 & 3.11 & 9 & Mutilation \\
\hline 3120 & 7.59 & -0.81 & 9 & Dead mutilated body \\
\hline 9140 & 7.77 & 9.56 & 8 & Dead cow \\
\hline 9410 & 8.21 & 7.13 & 8 & Soldier and dead child \\
\hline 6212 & 8.76 & 3.04 & 4 & Soldier and child \\
\hline 9042 & 9.3 & 0.82 & 9 & Stick through lip \\
\hline
\end{tabular}

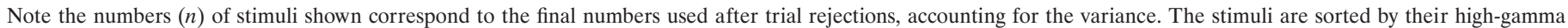
values; shaded stimuli show those used in our analyses of subcategories (compare with Results).

interaction was significant $\left(F_{(5,165)}=2.50 ; \epsilon=0.78 ; p<0.05\right)$. This was attributable to the fact that responses in the high gamma range were greater than in the low gamma range, especially at 150-450 msec after stimulus onset (compare with Fig. 3 ). The time $\times$ category interaction was also significant $\left(F_{(10,165)}=5.45\right.$; no correction; $p<0.001$ ), because the responses to aversive stimuli were much greater than to pleasant or neutral stimuli only in the poststimulus time windows. The two-way frequency $\times$ category interaction was not significant $\left(F_{(2,33)}=2.18\right.$; no correction; $\left.p=0.13\right)$. The threeway time $\times$ frequency $\times$ category interaction was also significant $\left(F_{(5,165)}=5.04 ; \epsilon=0.78 ; p<0.001\right)$, a consequence of a greater response in the low gamma range for aversive stimuli rather than pleasant or neutral stimuli especially in the window 150-250 msec after stimulus onset and in the high gamma range especially in the windows 150-250 and 350-450 msec after stimulus onset.

These results were confirmed by additional orthogonal one-way ANOVAs with a between-subject factor of emotion category (three levels) performed separately on the ERBP data obtained from each channel (averaged within the high or low gamma range across frequencies) for each of the five poststimulus time win- dows. For these ANOVAs, we set our $\alpha$ level at 0.005 to correct for inflation of type I errors attributable to multiple comparisons. These ANOVAs (Table 4) showed that in the low gamma range, responses differed significantly among emotion categories during the time windows of $50-150$ and $150-250 \mathrm{msec}$ after stimulus onset $\left(F_{(2,35)}=10.78, p<0.001 ; F_{(2,35)}=15.75, p<0.001\right.$, respectively). Post hoc Tukey's HSD tests revealed that these amygdala responses to aversive stimuli were significantly different from neutral or pleasant stimuli, but responses to neutral and pleasant stimuli did not differ $(50-150 \mathrm{msec}$ window, $p<0.05$ and 0.01 for aversive versus pleasant and aversive versus neutral, respectively; $150-250 \mathrm{msec}$ window; $p<0.01$ and 0.03 ). In the high gamma range, ERBP responses differed significantly among emotion categories during time windows of 150-250 and 350-450 msec after stimulus onset $\left(F_{(2,35)}=14.57, p<0.001 ; F_{(2,35)}=\right.$ $38.89, p<0.001$, respectively). As for responses in the low gamma range, significant responses in the high gamma range were also driven primarily by aversive stimuli $(150-250 \mathrm{msec}$ window, $p<0.01$ and $0.01 ; 350-450$ msec window, $p<0.01$ and 0.01 ; Tukey's HSD with the same emotion category contrasts as above) (Figs. 3, 4). 
$(\mathrm{Hz})$
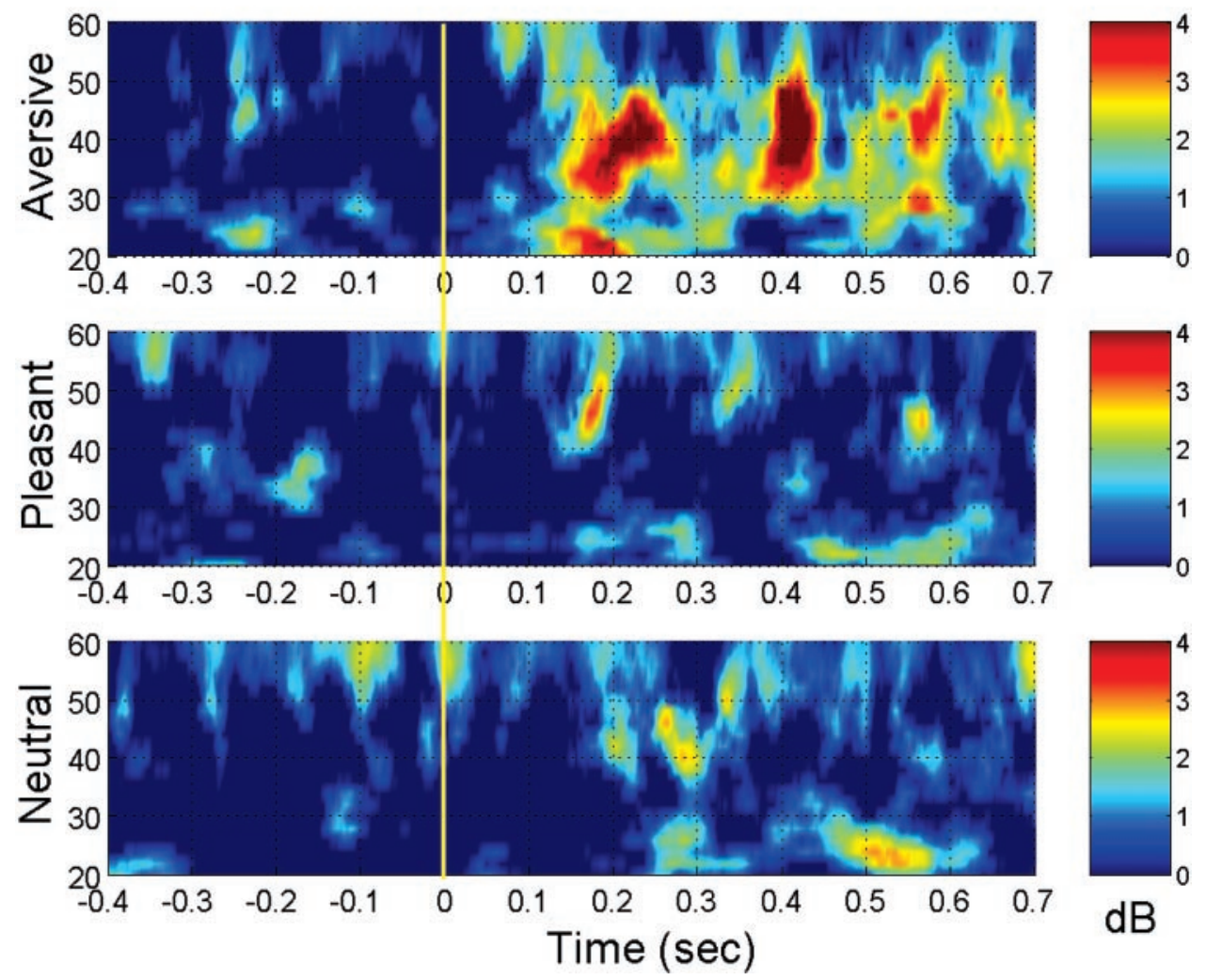

Figure 3. Time-frequency plots of ERBP values for each stimulus category. Time is shown on the $x$-axis (seconds), and frequency $(20-60 \mathrm{~Hz})$ is shown on the $y$-axis. Stimulus onset is indicated by the yellow vertical bar at 0 sec. Color encodes ERBP values in decibels. ERBP values were calculated for individual trials and subsequently averaged across 12 channels in which significant responses were seen relative to a 500 msec prestimulus reference period.

\section{Effect of repeated presentations}

Because stimuli were presented three times to patient 66 , we were in a position to examine whether there was any habituation of ERBP values with repeated presentations of the same stimulus. We calculated single-trial ERBP values in time windows of 150250 and $350-450 \mathrm{msec}$ in the higher gamma range and 50-150 and 150-250 msec in the lower gamma range and averaged over the two time windows within each frequency range for each stimulus (Table 5). These data were then used in one-way repeated measures ANOVAs with a factor of presentation order. There was no statistically significant mean ERBP change attributable to repeated presentation of the same stimuli (aversive: higher gamma, $F_{(2,50)}=0.602, p=0.552$; lower gamma, $F_{(2,50)}=$ $0.326, p=0.723$; pleasant: higher gamma, $F_{(2,38)}=2.193, p=$ 0.126 ; lower gamma, $F_{(2,38)}=1.118, p=0.337$; neutral: higher gamma, $F_{(2,36)}=0.752, p=0.479$; lower gamma, $F_{(2,36)}=0.779$, $p=0.467$; no correction of degrees of freedom was required for these analyses).

\section{Effect of stimulus valence, arousal, luminance, and color composition}

In addition to the above analyses of the effect of the stimulus emotion category, we examined the possible effects of stimulus valence and arousal as continuous measures on the ERBP responses in those time windows in which we had previously found significant responses as described above. Simple linear bivariate correlation analyses were performed for all trials in selected channels. Total ERBP values were calculated in time windows 3 and 5 (150-250 and 350-450 msec after stimulus onset) for responses in the higher gamma range and time windows 2 and 3 (50-150 and 150-250 msec after stimulus onset) for responses in the lower gamma range. There was a weak but significant corre- lation between these ERBP values in both gamma ranges and valence ratings of the stimuli (Spearman's $\rho$ : $-0.30 ; p<0.001$ for higher gamma; $r=-0.16 ; p<0.001$ for lower gamma; $n=829$ ) and between these ERBP values and arousal ratings $(r=0.25, p<$ 0.001 for higher gamma; $r=0.130, p<0.001$ for lower gamma; $n=829)$. The findings are thus consistent with the ones we reported above; highly arousing and negatively valenced stimuli (i.e., aversive stimuli) drive ERBP responses within the amygdala.

To control for possible effects of the physical properties of the images independently of their emotional meaning, we also performed such correlational analyses for stimulus luminance and color composition (red, green, and blue). There was no statistically significant correlation between ERBP values and global luminance level or individual luminance levels for each of the different color channels in the stimuli in both frequency ranges (global luminance, $r=-0.011, p=0.740$ for higher gamma; $r=$ $-0.010, p=0.770$ for lower gamma; red, $r=0.028, p=0.425 ; r=$ $0.017, p=0.620$; green, $r=-0.033, p=0.347 ; r=-0.032, p=$ 0.355 ; blue, $r=-0.018, p=0.605 ; r=-0.020, p=0.557$, respectively; $n=829$ for all coefficients). Thus, the effects reported above can be attributed to the emotional meaning of the stimuli and not to their incidental visual properties.

\section{Analysis of gamma phase (PLV)}

We examined the phase stability of responses in the gamma frequency band using PLV values (see Materials and Methods). Bias-corrected PLVs were calculated for each channel and $p$ values of these PLVs obtained from resampling statistics were averaged across channels and were plotted in color on the timefrequency plane (Fig. 5). We set $\alpha$ to 0.001 in these statistical analyses to avoid the possible inclusion of very brief occurrences of spurious phase locking. This analysis showed a complete ab- 
Table 4. ERBP responses in five poststimulus time epochs

\begin{tabular}{|c|c|c|c|c|c|}
\hline Band & Time epoch & & Aversive & Pleasant & Neutral \\
\hline \multirow[t]{15}{*}{ Low gamma } & $50-150$ & Mean & 2.04 & -0.34 & -0.69 \\
\hline & & SEM & 0.6 & 0.39 & 0.33 \\
\hline & & $p$ & & $<0.001^{*}$ & \\
\hline & $150-250$ & Mean & 3.41 & 0.95 & 0.28 \\
\hline & & SEM & 0.51 & 0.36 & 0.44 \\
\hline & & $p$ & & $<0.001^{*}$ & \\
\hline & $250-350$ & Mean & 2.12 & 0.08 & 1.53 \\
\hline & & SEM & 0.28 & 0.52 & 0.44 \\
\hline & & $p$ & & 0.107 & \\
\hline & $350-450$ & Mean & 1.94 & 0.45 & 1.1 \\
\hline & & SEM & 0.3 & 0.43 & 0.28 \\
\hline & & $p$ & & 0.096 & \\
\hline & $450-550$ & Mean & 2.14 & 0.77 & 2.29 \\
\hline & & SEM & 0.51 & 0.43 & 0.74 \\
\hline & & $p$ & & 0.134 & \\
\hline \multirow[t]{15}{*}{ High gamma } & $50-150$ & Mean & 0.61 & 0.11 & -0.27 \\
\hline & & SEM & 0.38 & 0.29 & 0.73 \\
\hline & & $p$ & & 0.244 & \\
\hline & $150-250$ & Mean & 4.52 & 0.7 & 1.16 \\
\hline & & SEM & 0.73 & 0.37 & 0.48 \\
\hline & & $p$ & & $<0.001^{*}$ & \\
\hline & $250-350$ & Mean & 2.62 & 0.64 & 1.9 \\
\hline & & SEM & 0.51 & 0.45 & 0.59 \\
\hline & & $p$ & & 0.035 & \\
\hline & $350-450$ & Mean & 4.51 & 0.03 & 0.16 \\
\hline & & SEM & 0.58 & 0.31 & 0.27 \\
\hline & & $p$ & & $<0.001^{*}$ & \\
\hline & $450-550$ & Mean & 2.42 & 0.43 & 0.69 \\
\hline & & SEM & 0.42 & 0.51 & 0.37 \\
\hline & & $p$ & & 0.006 & \\
\hline
\end{tabular}

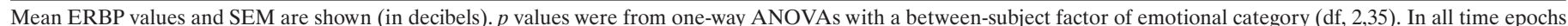

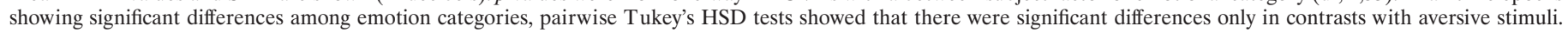
$* p<0.005$ was considered significant.

sence of any significant phase-locking state induced by the stimuli. Thus, field potential responses within the amygdala were not phase-locked to the onset of the stimuli (so-called "evoked" responses) but likely resulted from a temporally dispersed evaluation of their emotional meaning to give so-called "induced" responses (Galambos, 1992).

\section{Additional emotion categories revealed by analyses of ERBP responses}

Given our finding of ERBP responses relatively selective to aversive stimuli, we wondered whether all aversive stimuli contributed equally to this effect or whether additional analyses might reveal emotion subcategories in addition to those that we had predefined. We restricted this exploratory analysis to the aversive stimuli and to mean ERBP values of individual trials within those time windows in which we had previously found significant category responses (150-250 and 350-450 $\mathrm{msec}$ in the higher gamma frequency range and 50-150 and 150-250 msec in the lower gamma frequency range). ERBP values were examined for each of the different aversive stimulus images we used (see Table 2 for stimulus identifiers and a brief description of each stimulus). We divided the mean ERBP values of individual pictures within an emotion category into two further groups: the 10 with the highest mean response (HR) and the 10 with the lowest mean response (LR).
For responses in the higher gamma range, we found that images related to human injury occurred frequently in the HR group (8 of 10 stimuli), whereas images related to repulsion and disgust occurred frequently in the LR group (8 of 10 stimuli). Although these findings should be considered preliminary in view of the small numbers of stimuli, this pattern was nonetheless statistically significant when using an exact statistic (Fisher's exact test; $p=$ $0.012 ; n=20)$. There were no significant differences in luminance levels or in color composition between the HR and LR groups as shown by Mann-Whitney $U$ tests (luminance, $U=44.0, p=$ 0.650 ; red, $U=47.0, p=0.821$; green, $U=41.0, p=0.496$; blue, $U=38.0, p=0.272$ ), nor was there any correlation between ERBP values and luminance level or color composition for the 10 images in either group (Spearman's $\rho$ : luminance, $r=-0.023, p=$ 0.925 ; red, $r=0.132, p=0.578$; green, $r=-0.041, p=0.865$; blue, $r=-0.102, p=0.670 ; n=20$ ). Identical analyses were also performed within the lower gamma range, but we found no significant pattern here.

To investigate the psychological validity of these possible stimulus subcategories reflected in neuronal activity patterns, we asked 10 naïve, normal subjects to sort randomized collections of our stimulus images into binary sets of piles (for details, see Materials and Methods). No instructions were given to the subjects, other than that they should sort the stimuli into the two 

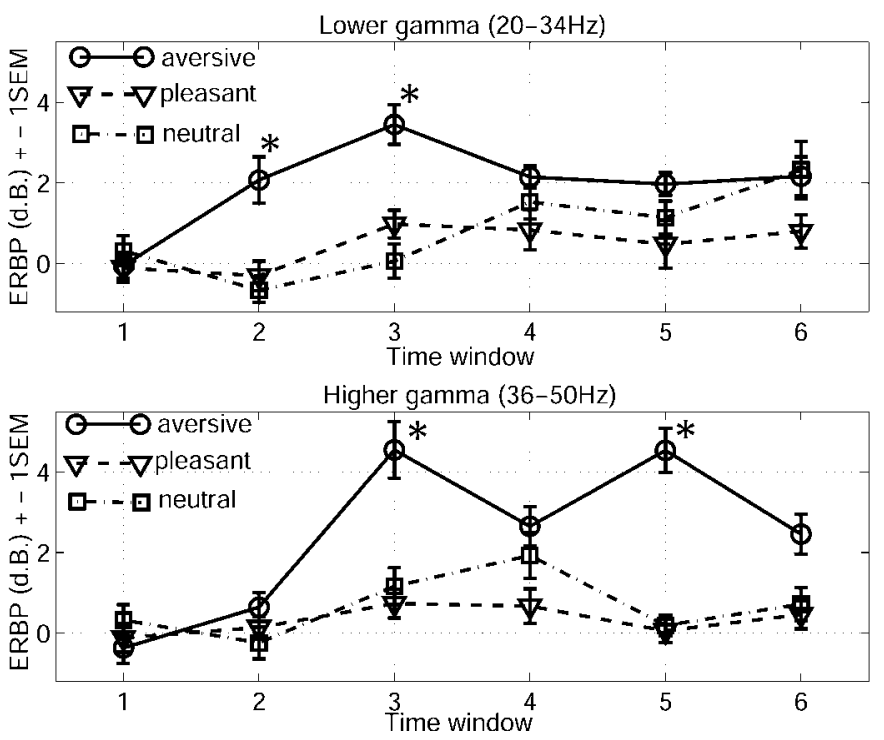

Figure 4. Time course of averaged ERBP values in six time windows (1, -100 to 0 msec; $2,50-150 \mathrm{msec} ; 3,150-250 \mathrm{msec} ; 4,250-350 \mathrm{msec} ; 5$, $350-450 \mathrm{msec}$; and $6,450-550 \mathrm{msec}$ ) for three emotion categories and two gamma frequency ranges (higher and lower gamma). *Statistically significant differences between emotion categories that were assessed by ANOVA with $\alpha=0.005$. Error bars represent 1 SEM $(n=12)$.

categories that, in their opinion, most clearly separated stimuli using whatever strategy seemed most salient to them. Subjects indeed sorted the stimuli into piles that bore similarity to the categories revealed by our analysis of the field potential data. Four of the 10 subjects created binary categories that overlapped significantly with those shown from the field potential data ( $p<0.05$; all other $p<0.2$, as calculated from the binomial distribution of their sorting). When subsequently asked what sorting strategy they had used, subjects provided a wide range of responses. No similarity was observed between the field potential categories and subject sortings in the case of pleasant and neutral stimuli (all $p>0.25$, binomial probability).

\section{DISCUSSION}

Our data support three conclusions: (1) gamma power envelope responses discriminate between stimuli in different emotion categories, with significant responses only to aversive stimuli; moreover, this response selectivity could not be attributed to differences in luminance or color between stimuli; (2) responses did not show significant phase locking [i.e., they were induced but not evoked (Galambos, 1992)]; and (3) a preliminary further analysis suggested that, within the aversive category, there were two potential subcategories that might be differentiated by neurons within the amygdala; moreover these categories were psychologically discriminated by naïve human subjects when asked to sort stimuli into piles, suggesting that they correspond to psychologically real categories. Possibly, one type of response was related to images depicting human injury, whereas another type of response was related to disgust. Taken together, the findings support the role of the amygdala in evaluating the emotional meanings of visual stimuli and corroborate its relative specialization for processing stimuli related to threat, danger, and aversion.

The possible contribution of our patients' epilepsy to abnormal electrical activity in the amygdala is an important concern. We addressed this issue in three ways. First, we recorded only during a stable interictal period (the experiments were postponed until at least $12 \mathrm{hr}$ after the occurrence of a seizure, and we ensured that no postictal symptoms were present). Second, detailed examination of the patients' preimplantation MR scans did not reveal any structural abnormality in the amygdala from which we obtained recordings. Third, we selected our patients to include only those who showed normal cognitive function on several neuropsychological tests and in whom the epileptogenic foci were distal to the amygdala (see Materials and Methods). It is also worth noting that any potentially abnormal electrical activity in extraamygdala tissue would be unlikely to influence our recordings, because we obtained bipolar differential recordings that measured only local field potentials adjacent to the recording contacts.

The local field potential (LFP) reflects current flow in the extracellular space resulting from synchronous dendritic and somatic activity within a relatively confined space proximal to the recording site (Bandettini and Ungerleider, 2001; Bressler and Kelso, 2001). We used the LFP to provide the first analysis of gamma band responses recorded in the human amygdala. Our analysis separated phase and amplitude components of the LFP, thus permitting independent examinations of these components. Oscillations recorded in summed neuronal activity can be classified as spontaneous, induced (not time-locked to the stimulus onset), or evoked (time-locked to the stimulus and generally evoked with a short latency $\sim 80-100 \mathrm{msec}$ after stimulus onset; Galambos, 1992). In our study, the PLV within the amygdala showed gamma band responses that appeared to be only of the induced type; that is, there was no phase locking evident, despite increased power density. However, it is important to point out that this negative finding is limited by our use of a large variety of different stimuli, and it remains possible that stimulus-induced phase locking would appear if the same stimulus were presented for a large number of repetitions. For instance, different stimuli may induce responses with slightly different temporal lags, and averaging over such responses would then wash out any stimuluslocked response pattern. We did examine this possibility further in the one patient in whom we were able to obtain triplicate recordings (patient 66); but here also, we found no evidence of stimulus-induced phase locking.

Investigations of phase-locking components (Jokeit and Makeig, 1994; Tallon-Baudry et al., 1996, 1997; Karakas and Basar, 1998) suggest that early (0-150 msec after stimulus onset) phase locking can occur irrespective of the type of stimulus, task demands, or perceptual situation, thus presumably reflecting early sensory processing driven solely by the stimulus features. However, at later times, responses can show an increased power density in the gamma frequency range without any phase locking; such induced gamma oscillations reflect temporally dispersed activity and appear to depend critically on task demands, attention, and the nature of the conscious percept. It is thus likely that such increased gamma power reflects cognitive processing (Karakas et al., 2001). Given that we found no evidence of stimuluslocked responses, the increased gamma power observed in the present study in response to aversive stimuli may represent one mechanism whereby neurons within the amygdala serve to bind perceptual visual representations of the configuration of stimulus features (via projections from temporal visual cortices) with the emotional and social knowledge relating to those stimuli. That is, the responses we observed do not just reflect visual drive from the stimulus but likely reflect the central computations that underlie the association of the visual stimulus with its emotional meaning. Consistent with this interpretation, it is notable that several of our recordings were from the medial aspect of the amygdala and 
Table 5. ERBP data for the analysis of repeated stimulus presentations

\begin{tabular}{|c|c|c|c|c|c|c|c|c|c|c|}
\hline \multirow[b]{2}{*}{ Category } & \multirow{2}{*}{$\begin{array}{l}\text { Frequency } \\
\text { band }\end{array}$} & \multicolumn{3}{|c|}{ First presentation } & \multicolumn{3}{|c|}{ Second presentation } & \multicolumn{3}{|c|}{ Third presentation } \\
\hline & & Mean & SEM & $n$ & Mean & SEM & $n$ & Mean & SEM & $n$ \\
\hline \multirow[t]{2}{*}{ Aversive } & Low gamma & 2.56 & 1.12 & 30 & 1.54 & 0.78 & 30 & 2.77 & 1.28 & 26 \\
\hline & High gamma & 4.85 & 0.81 & 30 & 6.28 & 0.92 & 30 & 4.66 & 1.19 & 26 \\
\hline \multirow[t]{2}{*}{ Pleasant } & Low gamma & -0.71 & 1.03 & 30 & 0.75 & 0.98 & 28 & -0.49 & 1.25 & 20 \\
\hline & High gamma & 1.28 & 0.85 & 30 & 0.56 & 0.84 & 28 & -1.14 & 0.85 & 20 \\
\hline \multirow[t]{2}{*}{ Neutral } & Low gamma & -1.14 & 1.18 & 30 & -1.67 & 1.01 & 28 & -0.19 & 1.57 & 19 \\
\hline & High gamma & 0.79 & 0.71 & 30 & -0.76 & 0.79 & 28 & -0.36 & 0.92 & 19 \\
\hline
\end{tabular}

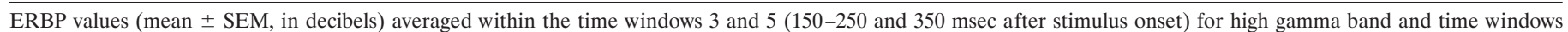

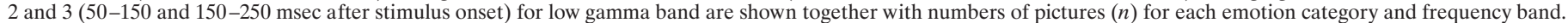

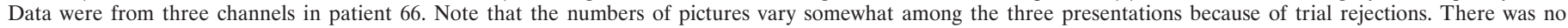
significant effect of stimulus presentation order.

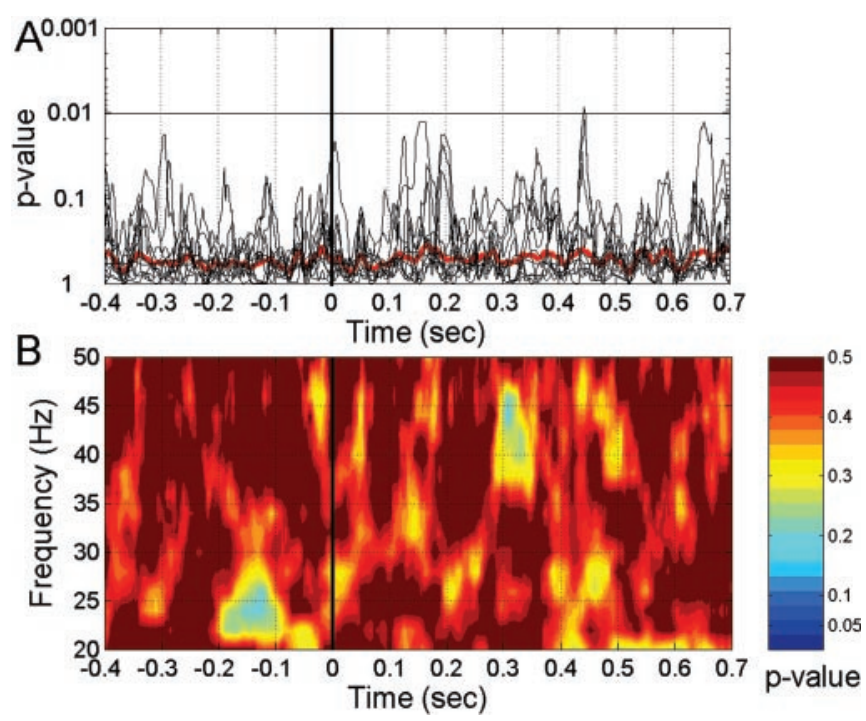

Figure 5. Phase analysis of responses in the gamma band. A, PLVs of 12 individual channels (thin black lines) and their mean PLV (thick red line) in response to aversive stimuli. The center frequency of the wavelet used in the analysis is $40 \mathrm{~Hz}$. $B$, PLV for aversive stimuli, averaged across 12 channels, plotted in the time-frequency plane. Color represents the $p$ value of PLV. $p$ values were calculated from the resampling distribution of the $500 \mathrm{msec}$ prestimulus period. No significant phase locking was observed.

are thus unlikely, on anatomical grounds, to reflect simply visual input from temporal association cortices.

Our findings are in line with recent functional imaging studies of the human amygdala, which have shown that amygdala activation reflects the integration of perceptual information with emotional associations for the stimuli (Büchel et al., 1998; LaBar et al., 1998; Phelps et al., 2001), and that such activation occurs even under passive viewing conditions (Breiter et al., 1996), as we used in the present study. There are some important outstanding issues regarding the role of the amygdala in processing emotional information. First, is there hemispheric asymmetry? Most functional imaging studies using emotional faces as stimuli have reported left amygdala activation, and Morris et al. (1998) showed differential activation of the right and left amygdala for subliminally and supraliminally presented stimuli, respectively. Although our small sample of recording sites precludes such analyses, it is interesting to note that we also obtained robust responses from the left amygdala, consistent with the above findings.

A second issue of interest concerns processing by the amygdala of positively valenced emotional information. Although most functional imaging and lesion studies in humans have focused on the participation of the amygdala in processing aversive stimuli, several recent reports have found responses also to highly arousing, positively valenced stimuli, for instance, sexually explicit movies or pictures (Hamann et al., 1999; Beauregard et al., 2001; Garavan et al., 2001; Aalto et al., 2002; Hamann et al., 2002). One possible explanation for our failure to find amygdala responses to positive stimuli may thus be that our pleasant stimuli did not contain sexually or otherwise sufficiently arousing exemplars.

The category selectivity of the responses we observed deserves further comment. The amygdala appears to contain neurons that respond selectively to a variety of complex visual stimuli (Fried et al., 1997; Kreiman et al., 2000) and appears to be able to do so in large part by virtue of the motivational value with which such stimuli have been associated (Nishijo et al., 1988). Functional imaging studies in humans present a somewhat bewildering array of amygdala responses to visual stimuli: to lexical threat (Isenberg et al., 1999), facial expressions of fear (Breiter et al., 1996; Morris et al., 1996; Whalen et al., 1998, 2001), faces of another race (Hart et al., 2000; Phelps et al., 2000), faces judged to look untrustworthy (Winston et al., 2002), aversive visual stimuli (Irwin et al., 1996; Lane et al., 1997; Liberzon et al., 2000), and in some studies any salient visual stimulus (Phillips et al., 1998). How can these findings be reconciled? We propose the following sketch. First, different nuclei within the amygdala, and possibly even different pools of neurons within a nucleus, may process somewhat different aspects of a stimulus. Second, the presence in our study, in the same field potentials, of responses to subcategories of aversive stimuli suggests that neurons within the amygdala are able to signal information about multiple aspects of the emotional meaning of a stimulus. Third, despite this complexity, all responses we found (as well as those in the majority of other studies) point to a relatively specialized role in processing stimuli of negative valence and high arousal. Given these results, the amygdala might be thought of as a conglomerate of interlocked functional modules that process different aspects of information about the potential threat, danger, aversion, or repulsion signaled by a stimulus (and perhaps extend even to processing highly arousing, positively valenced stimuli). It seems likely that the functions of different amygdala neurons in this respect are probably not rigid but rather are dynamically reorganizable depending on cognitive demand. Future studies that present stimuli under a variety of task demands and that examine responses from single neurons, some of which are currently under way in our laboratory, could investigate these issues in more detail. 


\section{REFERENCES}

Aalto S, Näätänen P, Wallius E, Metsähonkala L, Stenman H, Niem PM, Karlsson H (2002) Neuroanatomical substrata of amusement and sadness: a PET activation study using film stimuli. NeuroReport 13:67-73.

Adolphs R, Tranel D, Damasio H, Damasio A (1994) Impaired recognition of emotion in facial expressions following bilateral damage to the human amygdala. Nature 372:669-672.

Bagiella E, Sloan RP, Heitjan DF (2000) Mixed-effects models in psychophysiology. Psychophysiology 37:13-20.

Bandettini PA, Ungerleider LG (2001) From neuron to BOLD: new connections. Nat Neurosci 4:864-866.

Beauregard M, Lévesque J, Bourgouin P (2001) Neural correlates of conscious self-regulation of emotion. J Neurosci 21:RC165:1-6.

Bouyer JJ, Montaron MF, Vahnee JM, Albert MP, Rougeul A (1987) Anatomical localization of cortical beta rhythms in cat. Neuroscience 22:863-869.

Breiter HC, Etcoff NL, Whalen PJ, Kennedy WA, Rauch SL, Buckner RL, Strauss MM, Hyman SE, Rosen BR (1996) Response and habituation of the human amygdala during visual processing of facial expression. Neuron 17:875-887.

Bressler SL, Kelso JA (2001) Cortical coordination dynamics and cognition. Trends Cogn Sci 5:26-36.

Büchel C, Morris J, Dolan RJ, Friston KJ (1998) Brain systems mediating aversive conditioning: an event-related fMRI study. Neuron 20:947-957.

Buzsaki G (1986) Hippocampal sharp waves: their origin and significance. Brain Res 398:242-252.

Calder AJ, Young AW, Rowland WA, Perrett DI, Hodges JR, Etcoff NL (1996) Facial emotion recognition after bilateral amygdala damage: differentially severe impairment of fear. Cognit Neuropsychol 13:699-745.

Carmona R, Hwang W-L, Torrésani B (1998) Practical time-frequency analysis: Gabor and wavelet transforms with an implementation in S. San Diego: Academic.

Chrobak JJ, Buzsaki G (1998) Gamma oscillations in the entorhinal cortex of the freely behaving rat. J Neurosci 18:388-398.

Csibra G, Davis G, Spratling MW, Johnson MH (2000) Gamma oscillations and object processing in the infant brain. Science 290: $1582-1585$.

Damasio H, Frank R (1992) Three-dimensional in vivo mapping of brain lesions in humans. Arch Neurol 49:137-143.

Eckhorn R (1994) Oscillatory and non-oscillatory synchronizations in the visual cortex and their possible roles in associations of visual features. Prog Brain Res 102:405-426.

Eeckman FH, Freeman WJ (1990) Correlations between unit firing and EEG in the rat olfactory system. Brain Res 528:238-244.

Efron B (1979) 1977 Rietz Lecture: bootstrap methods—another look at the jackknife. Ann Stat 7:1-26.

Fernández T, Harmony T, Rodríguez M, Bernal J, Silva J, Reyes A, Marosi E (1995) EEG activation patterns during the performance of tasks involving different components of mental calculation. Electroencephalogr Clin Neurophysiol 94:175-182.

Frank RJ, Damasio H, Grabowski TJ (1997) Brainvox: an interactive, multimodal visualization and analysis system for neuroanatomical imaging. NeuroImage 5:13-30.

Freeman WJ (1972) Measurement of oscillatory responses to electrical stimulation in olfactory bulb of cat. J Neurophysiol 35:762-779.

Fried I, MacDonald KA, Wilson CL (1997) Single neuron activity in human hippocampus and amygdala during recognition of faces and objects. Neuron 18:753-765.

Galambos R (1992) A comparison of certain gamma band $(40 \mathrm{~Hz})$ brain rhythms in cat and man. In: Induced rhythms in the brain (Basar E, Bullock TH, eds), pp 201-216. Boston: Birkhauser.

Garavan H, Pendergrass JC, Ross TJ, Stein EA, Risinger RC (2001) Amygdala response to both positively and negatively valenced stimuli. NeuroReport 12:2779-2783.

Gasser T, Bacher P, Mocks J (1982) Transformations towards the normal distribution of broad band spectral parameters of the EEG. Electroencephalogr Clin Neurophysiol 53:119-124.

Gray CM, Konig P, Engel AK, Singer W (1989) Oscillatory responses in cat visual cortex exhibit inter-columnar synchronization which reflects global stimulus properties. Nature 338:334-337.

Hamann SB, Ely TD, Grafton ST, Kilts CD (1999) Amygdala activity related to enhanced memory for pleasant and aversive stimuli. Nat Neurosci 2:289-293.

Hamann SB, Ely TD, Hoffman JM, Kilts CD (2002) Ecstasy and agony: activation of the human amygdala in positive and negative emotion. Psychol Sci 13:135-141.

Hart AJ, Whalen PJ, Shin LM, McInerney SC, Fischer H, Rauch SL (2000) Differential response in the human amygdala to racial outgroup vs ingroup face stimuli. NeuroReport 11:2351-2355.

Howard MA, Volkov IO, Granner MA, Damasio HM, Ollendieck MC, Bakken HE (1996) A hybrid clinical-research depth electrode for acute and chronic in vivo microelectrode recording of human brain neurons. J Neurosurg 84:129-132.

Huynh H, Feldt LS (1980) Performance of traditional F-tests in repeated measures designs under covariance heterogeneity. Comm Stat A Theory Methods 9:61-74.

Irwin W, Davidson RJ, Lowe MJ, Mock BJ, Sorenson JA, Turski PA (1996) Human amygdala activation detected with echo-planar functional magnetic resonance imaging. NeuroReport 7:1765-1769.

Isenberg N, Silbersweig D, Engelien A, Emmerich S, Malavade K, Beattie B, Leon AC, Stern E (1999) Linguistic threat activates the human amygdala. Proc Natl Acad Sci USA 96:10456-10459.

Jokeit H, Makeig S (1994) Different event-related patterns of gammaband power in brain waves of fast- and slow-reacting subjects. Proc Natl Acad Sci USA 91:6339-6343.

Jones MS, Barth DS (1997) Sensory-evoked high-frequency (gammaband) oscillating potentials in somatosensory cortex of the unanesthetized rat. Brain Res 768:167-176.

Karakas S, Basar EC (1998) Early gamma response is sensory in origin: a conclusion based on cross-comparison of results from multiple experimental paradigms. Int J Psychophysiol 31:13-31.

Karakas S, Basar EC, Özesmi C, Kafadar H, Erzengin ÖÜ (2001) Gamma response of the brain: a multifunctional oscillation that represents bottom-up with top-down processing. Int $\mathrm{J}$ Psychophysiol 39:137-150

Kawasaki H, Kaufman O, Damasio H, Damasio AR, Granner M, Bakken H, Hori T, Howard MA, Adolphs R (2001) Single-neuron responses to emotional visual stimuli recorded in human ventral prefrontal cortex. Nat Neurosci 4:15-16.

Keil A, Müller MM, Gruber T, Wienbruch C, Stolarova M, Elbert T (2001) Effects of emotional arousal in the cerebral hemispheres: a study of oscillatory brain activity and event-related potentials. Clin Neurophysiol 112:2057-2068.

Kreiman G, Koch C, Fried I (2000) Category-specific visual responses of single neurons in the human medial temporal lobe. Nat Neurosci 3:946-953.

Kubota Y, Sato W, Murai T, Toichi M, Ikeda A, Sengoku A (2000) Emotional cognition without awareness after unilateral temporal lobectomy in humans. J Neurosci 20:RC97:1-5.

LaBar KS, Gatenby JC, Gore JC, LeDoux JE, Phelps EA (1998) Human amygdala activation during conditioned fear acquisition and extinction: a mixed-trial fMRI study. Neuron 20:937-945.

Lachaux JP, Rodriguez E, Martinerie J, Varela FJ (1999) Measuring phase synchrony in brain signals. Hum Brain Mapp 8:194-208.

Lane RD, Reiman EM, Ahern GL, Schwartz GE, Davidson RJ (1997) Neuroanatomical correlates of happiness, sadness, and disgust. Am J Psychiatry 154:926-933.

Lang PJ, Cuthbert BN (1993) International affective picture system standardization procedure and initial group results for affective judgements: technical report. Gainesville, FL: University of Florida.

Lang PJ, Greenwald MK, Bradley MM, Hamm AO (1993) Looking at pictures: affective, facial, visceral, and behavioral reactions. Psychophysiology 30:261-273.

Le Van Quyen M, Foucher J, Lachaux J, Rodriguez E, Lutz A, Martinerie J, Varela FJ (2001) Comparison of Hilbert transform and wavelet methods for the analysis of neuronal synchrony. J Neurosci Methods 111:83-98.

LeDoux JE (1996) The emotional brain: the mysterious underpinnings of emotional life. New York: Simon and Schuster.

Liberzon I, Taylor SF, Fig LM, Decker LR, Koeppe RA, Minoshima S (2000) Limbic activation and psychophysiologic responses to aversive visual stimuli: interaction with cognitive task. Neuropsychopharmacology 23:508-516.

MacDonald KD, Brett B, Barth DS (1996) Inter- and intra-hemispheric spatiotemporal organization of spontaneous electrocortical oscillations. J Neurophysiol 76:423-437.

MacDonald KD, Fifkova E, Jones MS, Barth DS (1998) Focal stimulation of the thalamic reticular nucleus induces focal gamma waves in cortex. J Neurophysiol 79:474-477.

Macwhinney B, Cohen J, Provost J (1997) The PsyScope experimentbuilding system. Spatial Vision 11:99-101.

Mallat SG (1998) A wavelet tour of signal processing. San Diego: Academic.

Manly BFJ (1997) Randomization, bootstrap, and Monte Carlo methods in biology, Ed 2. London: Chapman and Hall.

Miltner WH, Braun C, Arnold M, Witte H, Taub E (1999) Coherence of gamma-band EEG activity as a basis for associative learning. Nature 397:434-436.

Morris JS, Frith CD, Perrett DI, Rowland D, Young AW, Calder AJ, Dolan RJ (1996) A differential neural response in the human amygdala to fearful and happy facial expressions. Nature 383:812-815.

Morris JS, Ohman A, Dolan RJ (1998) Conscious and unconscious emotional learning in the human amygdala. Nature 393:467-470.

Müller MM, Keil A, Gruber T, Elbert T (1999) Processing of affective pictures modulates right-hemispheric gamma band EEG activity. Clin Neurophysiol 110:1913-1920. 
Müller MM, Gruber T, Keil A (2000) Modulation of induced gamma band activity in the human EEG by attention and visual information processing. Int J Psychophysiol 38:283-299.

Murthy VN, Fetz EE (1992) Coherent 25- to 35-Hz oscillations in the sensorimotor cortex of awake behaving monkeys. Proc Natl Acad Sci USA 89:5670-5674.

Nishijo H, Ono T, Nishino H (1988) Single neuron responses in amygdala of alert monkey during complex sensory stimulation with affective significance. J Neurosci 8:3570-3583.

Northoff G, Richter A, Gessner M, Schlagenhauf F, Fell J, Baumgart F, Kaulisch T, Kötter R, Stephan KE, Leschinger A, Hagner T, Bargel B, Witzel T, Hinrichs H, Bogerts B, Scheich H, Heinze HJ (2000) Functional dissociation between medial and lateral prefrontal cortical spatiotemporal activation in negative and positive emotions: a combined fMRI/MEG study. Cereb Cortex 10:93-107.

O’Doherty J, Rolls ET, Francis S, Bowtell R, McGlone F (2001) Representation of pleasant and aversive taste in the human brain. J Neurophysiol 85:1315-1321.

Phelps EA, O'Connor KJ, Cunningham WA, Funayama ES, Gatenby JC, Gore JC, Banaji MR (2000) Performance on indirect measures of race evaluation predicts amygdala activation. J Cogn Neurosci 12:729-738.

Phelps EA, O'Connor KJ, Gatenby JC, Gore JC, Grillon C, Davis M (2001) Activation of the left amygdala to a cognitive representation of fear. Nat Neurosci 4:437-441.

Phillips ML, Young AW, Scott SK, Calder AJ, Andrew C, Giampietro V, Williams SC, Bullmore ET, Brammer M, Gray JA (1998) Neural responses to facial and vocal expressions of fear and disgust. Proc R Soc Lond B Biol Sci 265:1809-1817.

Rodriguez E, George N, Lachaux JP, Martinerie J, Renault B, Varela FJ (1999) Perception's shadow: long-distance synchronization of human brain activity. Nature 397:430-433.

Roelfsema PR, Engel AK, König P, Singer W (1997) Visuomotor integration is associated with zero time-lag synchronization among cortical areas. Nature 385:157-161.

Rolls ET (1999) The brain and emotion. Oxford: Oxford UP.

Rosenblum MG, Kurths J, Pikovsky A, Schafer C, Tass P, Abel HH (1998) Synchronization in noisy systems and cardiorespiratory interaction. IEEE Eng Med Biol Mag 17:46-53.

Royet JP, Zald D, Versace R, Costes N, Lavenne F, Koenig O, Gervais R (2000) Emotional responses to pleasant and unpleasant olfactory, visual, and auditory stimuli: a positron emission tomography study. J Neurosci 20:7752-7759.

Russell JA, Carroll JM (1999) On the bipolarity of positive and negative affect. Psychol Bull 125:3-30.

Sannita WG (2000) Stimulus-specific oscillatory responses of the brain: a time/frequency-related coding process. Clin Neurophysiol 111:565-583.

Sinkkonen J, Tiitinen H, Näätänen R (1995) Gabor filters: an informa- tive way for analysing event-related brain activity. J Neurosci Methods 56:99-104

Tallon-Baudry C, Bertrand O, Bouchet P, Pernier J (1995) Gammarange activity evoked by coherent visual stimuli in humans. Eur J Neurosci 7:1285-1291.

Tallon-Baudry C, Bertrand O, Delpuech C, Pernier J (1996) Stimulus specificity of phase-locked and non-phase-locked $40 \mathrm{~Hz}$ visual responses in human. J Neurosci 16:4240-4249.

Tallon-Baudry C, Bertrand O, Delpuech C, Pernier J (1997) Oscillatory $\gamma$-band $(30-70 \mathrm{~Hz})$ activity induced by a visual search task in humans. J Neurosci 17:722-734.

Tass P, Rosenblum MG, Weule J, Kurths J, Pikovsky A, Volkmann J, Schnitzler A, Freund HJ (1998) Detection of n:m phase locking from noisy data: application to magnetoencephalography. Physical Rev Lett 81:3291-3294.

Taylor SF, Liberzon I, Koeppe RA (2000) The effect of graded aversive stimuli on limbic and visual activation. Neuropsychologia 38:1415-1425.

Teolis A (1998) Computational signal processing with wavelets. Boston: Birkhauser.

Tiitinen H, Sinkkonen J, Reinikainen K, Alho K, Lavikainen J, Näätänen R (1993) Selective attention enhances the auditory 40-Hz transient response in humans. Nature 364:59-60.

Traub RD, Whittington MA, Colling SB, Buzsaki G, Jefferys JG (1996) Analysis of gamma rhythms in the rat hippocampus in vitro and in vivo. J Physiol (Lond) 493:471-484.

Wei J, Zhao L, Yan G, Duan R, Li D (1998) Temporal and spatial features of event related EEG spectral changes in 4 mental conditions. Electroencephalogr Clin Neurophysiol 106:416-423.

Weiskrantz L (1956) Behavioral changes associated with ablation of the amygdaloid complex in monkeys. J Comp Physiol Psychol 49:381-418.

Whalen P, Shin LM, McInerney SC, Fischer H, Wright CI, Rauch SL (2001) A functional MRI study of human amygdala responses to facial expressions of fear versus anger. Emotion 1:70-83.

Whalen PJ, Rauch SL, Etcoff NL, McInerney SC, Lee MB, Jenike MA (1998) Masked presentations of emotional facial expressions modulate amygdala activity without explicit knowledge. J Neurosci 18:411-418.

Winston JS, Strange BA, O'Doherty J, Dolan RJ (2002) Automatic and intentional brain responses during evaluation of trustworthiness of faces. Nat Neurosci 5:277-283.

Yee PL, Vaughan J (1999) A Web-accessible tutorial for PsyScope based on classic experiments in human cognition. Behav Res Methods Instrum Comput 31:107-112.

Zald DH, Pardo JV (1997) Emotion, olfaction, and the human amygdala: amygdala activation during aversive olfactory stimulation. Proc Natl Acad Sci USA 94:4119-4124.

Zald DH, Lee JT, Fluegel KW, Pardo JV (1998) Aversive gustatory stimulation activates limbic circuits in humans. Brain 121:1143-1154. 